\title{
Combined application of Glomus sp. and Pasteuria penetrans for reducing Meloidogyne incognita (Tylenchida: Meloidogynidae) populations and improving tomato growth
}

\author{
Miguel Talavera, Kenji Itou and Takayuki Mizukubo \\ Nematology Laboratory, Department of Entomology and Nematology, National Agricultural Research Center, Tsukuba, Ibaraki \\ 305-8666, Japan
}

(Received 25 June 2001; Accepted 15 October 2001)

\begin{abstract}
The beneficial effects of application of spores of the mycorrhizal fungus Glomus sp. and the nematode parasitic bacterium Pasteuria penetrans to Meloidogyne incognita-infested soil on tomato growth and nematode reproduction were assessed in pot and microplot experiments. Tomato shoot and fruit weights in $M$. incognita-infected plants receiving a combined application of Glomus sp. and P. penetrans were greater than in untreated nematode-infected plants. In addition, the use of the mycorrhizal fungus and the nematode parasitic bacterium together conferred greater beneficial effects than their use alone. Final densities of $M$. incognita juveniles in soil were lower than the control by $40 \%$ and $18 \%$ in mycorrhizal plants (cvs. Kyoryoku-beiju and Pritz, respectively), by $38 \%$ and $53 \%$ in P. penetrans application, and by $61 \%$ and $57 \%$, when both treatments were applied together. M. incognita did not affect root colonization by Glomus sp. when mycorrhizal inoculum was added two or three weeks before nematode inoculum. No significant effects of the mycorrhizal treatment on P. penetrans attachment to $M$. incognita or number of females infected by $P$. penetrans were observed.
\end{abstract}

Key words: Biological control, Glomus sp., Meloidogyne incognita, Pasteuria, tomato

\section{INTRODUCTION}

Pasteuria penetrans (Thorne) Sayre and Starr, the hyperparasite of Meloidogyne spp., has been associated with beneficial effects for nematode control in greenhouse and field experiments (Chen and Dickson, 1998). Spore concentrations between $5 \times 10^{4}$ and $5 \times 10^{5}$ per $g$ of soil provided immediate control of root-knot nematode populations in the field (Stirling, 1984; Stirling et al., 1990; Chen et al., 1996). The lack of large-scale production of inoculum, however, makes such applications difficult and too costly. On the other hand, population densities of $P$. penetrans increase gradually over time from relatively low densities of spores in the soil, reaching suppressive levels after several crop cycles (Oostendorp et al., 1991; Verdejo-Lucas, 1992); $10^{3}$ endospores per $g$ of soil amplified on $M$. arenaria infecting peanut and became suppressive after 3 years (Chen et al., 1996). Therefore, when low concentrations of spores are applied to field soil, additional measures are needed to increase the effectiveness of the bacteria and reduce the damage caused by the nematode during the first years after application.

Arbuscular mycorrhizas (AM) are soil-borne fungi that establish an obligate mutualistic symbiosis with many plant species. They are characterized by transient dichotomously-branched arbuscules that form inside cortical cells of plant roots from intraradical branch hyphae. AM are commonly associated with the roots of over $90 \%$ of plant species, and numerous studies have reported that AM increase host tolerance in some plant-nematode associations (Hooker et al., 1994; AzcónAguilar and Barea, 1996; Talavera et al., 2001). Glomus species are the most diverse of the AM and are found in many soils all over the world.

Very little is known about the beneficial effects of applying $P$. penetrans and AM together to soils with populations of Meloidogyne spp. In a pot experiment application, AM was associated with greater attachment of Pasteuria spores to juveniles of M. incognita (Kofoid and White) Chitwood (Rao and Gowen, 1998).

The objective of this work was to assess the beneficial effects of the use of $P$. penetrans and Glomus sp. on tomato growth and nematode reproduc- 
tion in soils infested with M. incognita.

\section{MATERIALS AND METHODS}

Pot experiments. Two pot experiments using two different cultivars of tomato (Lycopersicum esculentum Mill.), cv. Kyoryoku-beiju (Takii Seeds Co., Japan) and cv. Pritz (Kaneko Seeds Co. Ltd., Japan) were carried out to test the effects of root colonization by Glomus sp. and application of $P$. penetrans spores to soil on tomato growth and $M$. incognita reproduction.

Tomato seeds were germinated in vermiculite and grown for $7-14 \mathrm{~d}$ in a growth chamber at $25^{\circ} \mathrm{C}$. Seedlings at the three leaf stage were transplanted to individual plastic pots $(12 \mathrm{~cm}$ diameter $\times 15 \mathrm{~cm}$ height) filled with $1,000 \mathrm{~g}$ of a sterile clay-loam soil ( $40 \%$ sand : $30 \%$ silt : $30 \%$ clay).

Pots were treated with Glomus sp., P. penetrans and/or $M$. incognita for a total of six treatments: 1) Sterile soil (control); 2) Glomus sp.; 3) M. incognita; 4) M. incognita+Glomus sp.; 5) M. incognita + P. penetrans, and 6) M. incognita + Glomus sp. + P. penetrans.

Inocula of Glomus sp. R10 ATCC-74311 kindly provided by Idemitsu Kosan Co., Japan, and cultured on sorghum (Sorghum bicolor Moench.), consisted of spores extracted from soil around the roots of sorghum. Spores were extracted from soil by sucrose density gradient centrifugation, washed and stored in tap water at $4^{\circ} \mathrm{C}$ for $24 \mathrm{~h}$ before the seedlings were inoculated (Jarstfer and Sylvia, 1997). At the time of transplanting, $298 \pm 23$ spores were placed along the length of the tomato roots with a pipette. Non-mycorrhizal seedlings were treated with a suspension from the mycorrhizal extraction without mycorrhizal propagules. In the experiment with tomato cv. Kyoryoku-beiju, soil for mycorrhizal treatments was additionally mixed with Glomus sp. inoculum at a concentration of two spores per $\mathrm{g}$ of soil.

A commercial inoculum of $P$. penetrans (Pastoria, Nematec Co., Ltd., Japan) containing $10^{9}$ spores per $g$ was used to prepare a suspension with $5 \times 10^{5}$ spores per $\mathrm{ml}$. One hundred milliliters of suspension $\left(5 \times 10^{7}\right.$ spores $)$ was poured over the soil contained in each pot, $10 \mathrm{~d}$ after transplanting of the tomato seedlings. Pots not receiving viable $P$. penetrans spores were treated with a spore suspension that had been previously autoclaved twice at $120^{\circ} \mathrm{C}$ for $20 \mathrm{~min}$.

Second stage juveniles $\left(\mathrm{J}_{2}\right)$ of $M$. incognita were collected from egg masses $24-72 \mathrm{~h}$ after hatching. A suspension of $1,000 \mathrm{~J}_{2}$ in $10 \mathrm{ml}$ of water was pipetted to four holes of $5 \mathrm{~cm}$ soil-depth around the stem of the tomato seedling, $14 \mathrm{~d}$ after transplanting. Pots not receiving nematodes were treated in the same way with $10 \mathrm{ml}$ of water.

Each treatment was replicated four times. Pots were arranged on a glasshouse bench in a randomised-block design, with $10 \mathrm{~cm}$ between each pot. The temperature in the glasshouse during the experiment was $25 \pm 2^{\circ} \mathrm{C}$ ( $16 \mathrm{~h}$ photoperiod). Plants were watered daily to field capacity and after nematode inoculation fertilized weekly with $50 \mathrm{ml}$ of 1/1,000 diluted Hyponex 5-10-5 (Hyponex Japan Co., Inc., Japan). The experiments were repeated once.

Tomato cv. Kyoryoku-beiju and cv. Pritz plants were harvested seven and nine weeks after nematode inoculation, respectively. Plants were cut at soil level and the shoots and fruits were weighed. Contents of each pot were sieved through a $2.5 \mathrm{~mm}$ mesh to separate roots from soil. Roots were washed free of soil and gall indices were determined using the Bridge and Page root-knot-rating chart from 0 to 10 (Bridge and Page, 1980). Roots were then cut in 1-2 cm lengths, mixed thoroughly and subsamples of $0.25 \mathrm{~g}$ of roots were taken to recover $M$. incognita females and assess mycorrhizal colonization. Non-mobile stages within the roots were determined by shredding $0.25 \mathrm{~g}$ of root samples in $100 \mathrm{ml}$ of water using a blender at maximum speed for $15 \mathrm{~s}$ twice. Eggs and $\mathrm{J}_{2}$ present in the suspension were counted under a stereomicroscope. Sieved soils were stored in bags for 7-10 d at $15-20^{\circ} \mathrm{C}$ prior to nematode extraction. Soils were mixed thoroughly and then nematodes were recovered from $20 \mathrm{~g}$ soil samples by the Baermann funnel technique $(72 \mathrm{~h})$. Nematode reproduction was estimated using the numbers of $\mathrm{J}_{2}$ per $g$ of soil, eggs $+J_{2}$ and females per $g$ of roots and eggs $+J_{2}$ per female.

Mycorrhizal colonization ( $\mathrm{M} \%=$ percentage of mycorrhizal roots) was assessed in $0.25 \mathrm{~g}$ root fragments from all mycorrhizal treatments. Roots were cleared with $10 \% \mathrm{KOH}$ in an autoclave liquid cycle at $120^{\circ} \mathrm{C}$ for $20 \mathrm{~min}$ and then stained with chlorazole black-e in lactoglycerol for $15 \mathrm{~min}$ in an autoclave at $120^{\circ} \mathrm{C}$ (Phillips and Hayman, 1970). 
Colonization of roots was estimated by the grid line intersect method (Giovannetti and Mosse, 1980).

P. penetrans infection was estimated by counting the number of $\mathrm{J}_{2}$ with attached spores and the number of spores per juvenile in a sample of $33 \mathrm{~J}_{2}$. In addition, 33 females extracted from roots were crushed on a slide with a cover glass and checked for spores or vegetative stages of $P$. penetrans.

Microplot experiment. A microplot experiment was conducted in 12 square concrete plots $(1 \mathrm{~m} \times 1 \mathrm{~m})$ infested with $M$. incognita $\left(2-3 \mathrm{~J}_{2}\right.$ per $\mathrm{g}$ of soil) at the National Agriculture Research Center, Tsukuba, Japan. Treatments were: 1) $M$. incognita (control); 2) M. incognita + Glomus sp.; 3) $M$. incognita $+P$. penetrans, and 4) $M$. incognita + Glomus sp. $+P$. penetrans. Treatments were replicated three times and locations were randomly chosen within the 12 possible plots.

Tomato cv. Kyoryoku-beiju seeds were germinated in vermiculite and grown in a growth chamber at $25^{\circ} \mathrm{C}$ for $21 \mathrm{~d}$. Seedlings at the three to five leaf stage were transplanted into plastic pots $(9 \mathrm{~cm}$ top diam. $\times 6.5 \mathrm{~cm}$ bottom diam. $\times 8 \mathrm{~cm}$ height) filled with $300 \mathrm{~cm}^{3}$ of a sterile clay-loam soil $(40 \%$ sand : $30 \%$ silt : $30 \%$ clay), one seedling per pot.

Tomato seedlings were inoculated with spores of Glomus sp. R10 ATCC-74311 at the time of transplanting to pots as previously described.

Three days before transplanting to the field, all microplots were fertilized with $100 \mathrm{~g}$ of a $(14: 14$ : 14) compound fertilizer (Hairakku 444, Mitsui Chemical Co., Japan). P. penetrans plots received a suspension of $5 \times 10^{9}$ endospores in $10 \mathrm{l}$ of water poured over the soil surface $\left(5 \times 10^{9}\right.$ spores $\left./ \mathrm{m}^{2}\right)$; non- $P$. penetrans plots received only $10 l$ of water. Mycorrhizal and non-mycorrhizal seedlings were transplanted to the microplots when tomato plants were six weeks old (June 19, 2000). Three tomato seedlings were planted per plot.

Tomato plants were harvested 12 weeks after transplanting to the microplots (September 11, 2000). Plant and fruit weights, nematode reproduction, mycorrhizal colonization and infection by $P$. penetrans were estimated as previously described.

Statistical analyses. Data for cv. Kyoryokubeiju in pots, microplots and cv. Pritz in pots were analysed separately by ANOVA. When $F$ values were significant, means were compared by the LSD test $(p \leq 0.05)$. Kolmogorov-Smirnov and Levene's tests were performed to check for normality and homocedasticity; if significant, numerical data were $\log _{10}(x+1)$ transformed and percentages arcsine square root transformed prior to being analysed by ANOVA. Similarity between experimental runs, tested by preliminary ANOVA using experimental runs as blocks, allowed the data to be combined for subsequent ANOVA. Kruskal-Wallis or Mann-Whitney tests were used for data that could not be analysed with parametric statistics.

\section{RESULTS}

Application of Glomus sp. alone (Gm) was not associated with an increase in shoot or fruit weight (Table 1). Root infection by M. incognita (Mi) reduced shoot and fruit weight compared to nonnematode controls.

No significant differences were found in shoot weight between nematode infected plants (Mi) and infected plants treated with Glomus sp. (Mi-Gm) or P. penetrans (Mi-Pp) alone, but the application of both micro-organisms together (Mi-Gm-Pp) was associated with greater shoot weights of cv. Kyoryoku-beiju in pot and microplot experiments.

Fruit yield from cv. Kyoryoku-beiju in pots was quite low and did not differ between treatments. However, in the microplot experiment, fruit yield in Glomus-Pasteuria plots was greater than in the plots that contained $M$. incognita alone. The use of Glomus and/or Pasteuria in M. incognita infested soil also prevented fruit yield reduction due to the nematode in cv. Pritz pots (Table 1).

The combined use of Glomus and Pasteuria also reduced the gall index. Treatments with the greatest gall ratings had the lowest shoot and fruit weights (Table 1).

For both cultivars in pot experiments, densities of $\mathrm{J}_{2}$ per $\mathrm{g}$ of soil or $\mathrm{J}_{2}+$ eggs per $\mathrm{g}$ of roots were greater in non-treated nematode-infected plants (Mi) than in Glomus sp. (Mi-Gm) or P. penetrans (Mi-Pp) ones (Table 2). There were no differences between Glomus (Mi-Gm) and Pasteuria (Mi-Pp) treatments, but when both treatments were applied together, the numbers of $\mathrm{J}_{2}$ in soil and roots were lower than treatments with Glomus or Pasteuria alone. Final nematode densities per pot (soil+ roots) of cv. Kyoryoku-beiju were lower by $34 \%$ in mycorrhizal plants, by $44 \%$ after $P$. penetrans ap- 
Table 1. Effects of Glomus sp., P. penetrans and M. incognita on tomato growth

\begin{tabular}{|c|c|c|c|c|c|c|}
\hline & \multicolumn{6}{|c|}{ Treatments $^{\mathrm{a}}$} \\
\hline & Control & $\mathrm{Gm}$ & $\mathrm{Mi}$ & Mi-Gm & Mi-Pp & Mi-Gm-Pp \\
\hline \multicolumn{7}{|c|}{ cv. Kyoryoku-beiju in pots } \\
\hline Shoot weight (g) & $40.0 \mathrm{a}$ & $42.6 \mathrm{a}$ & $18.5 \mathrm{c}$ & $19.3 \mathrm{c}$ & $21.4 \mathrm{c}$ & $26.8 \mathrm{~b}$ \\
\hline Fruit yield $(\mathrm{g})$ & $15.9 \mathrm{a}$ & $22.6 \mathrm{a}$ & - & $9.0 \mathrm{a}$ & $6.6 \mathrm{a}$ & $13.1 \mathrm{a}$ \\
\hline Gall index & - & - & $6.3 \mathrm{a}$ & $5.3 \mathrm{a}$ & $5.8 \mathrm{a}$ & $4.3 \mathrm{~b}$ \\
\hline \multicolumn{7}{|l|}{ cv. Pritz in pots } \\
\hline Shoot weight (g) & $40.5 \mathrm{a}$ & $42.6 \mathrm{a}$ & $23.7 \mathrm{~b}$ & $29.4 \mathrm{ab}$ & $35.1 \mathrm{ab}$ & $34.9 \mathrm{ab}$ \\
\hline Fruit yield $(\mathrm{g})$ & $114.7 \mathrm{a}$ & $163.3 \mathrm{a}$ & $39.3 \mathrm{~b}$ & $90.6 \mathrm{a}$ & $98.7 \mathrm{a}$ & $86.4 \mathrm{a}$ \\
\hline Gall index & - & - & $8.0 \mathrm{a}$ & $7.5 \mathrm{a}$ & $6.3 \mathrm{~b}$ & $6.3 \mathrm{~b}$ \\
\hline \multicolumn{7}{|c|}{ cv. Kyoryoku-beiju in microplots } \\
\hline Shoot weight (g) & - & - & $217.8 \mathrm{~b}$ & $251.1 \mathrm{~b}$ & $250.6 \mathrm{~b}$ & $377.8 \mathrm{a}$ \\
\hline Fruit yield $(\mathrm{g})$ & - & - & $117.4 \mathrm{~b}$ & $189.7 \mathrm{~b}$ & $192.8 \mathrm{~b}$ & $449.0 \mathrm{a}$ \\
\hline Gall index & - & - & $6.6 \mathrm{a}$ & $6.7 \mathrm{a}$ & $6.7 \mathrm{a}$ & $5.7 \mathrm{~b}$ \\
\hline
\end{tabular}

${ }^{a} \mathrm{Gm}$, inoculated with Glomus sp.; Mi, inoculated with M. incognita; Pp, inoculated with P. penetrans. Data are the means of eight replicates in the pot experiments and three replicates and three plants in the microplot experiment. Data in the same row followed by the same letter do not differ at the level of $p \leq 0.05$.

Table 2. Effects of Glomus sp. and P. penetrans on M. incognita reproduction on tomato

\begin{tabular}{|c|c|c|c|c|}
\hline & \multicolumn{4}{|c|}{ Treatments $^{\mathrm{a}}$} \\
\hline & $\mathrm{Mi}$ & Mi-Gm & Mi-Pp & Mi-Gm-Pp \\
\hline \multicolumn{5}{|l|}{ cv. Kyoryoku-beiju in pots } \\
\hline $\mathrm{J}_{2}$ per $\mathrm{g}$ of soil & $9.5 \times 10 \mathrm{a}$ & $5.7 \times 10 b$ & $5.9 \times 10^{2} \mathrm{~b}$ & $3.7 \times 10 \mathrm{c}$ \\
\hline $\mathrm{J}_{2}+$ eggs per $\mathrm{g}$ of roots & $1.3 \times 10^{4} \mathrm{a}$ & $8.9 \times 10^{3} \mathrm{~b}$ & $7.3 \times 10^{3} \mathrm{~b}$ & $5.7 \times 10^{3} \mathrm{c}$ \\
\hline Females per $\mathrm{g}$ of roots & $7.0 \times 10 \mathrm{a}$ & $5.7 \times 10 \mathrm{~b}$ & $6.7 \times 10$ a & $5.7 \times 10 \quad b$ \\
\hline Eggs per female & $1.9 \times 10^{2} \mathrm{a}$ & $1.6 \times 10^{2} \mathrm{a}$ & $1.1 \times 10^{2} \mathrm{~b}$ & $1.0 \times 10^{2} \mathrm{~b}$ \\
\hline \multicolumn{5}{|l|}{ cv. Pritz in pots } \\
\hline $\mathrm{J}_{2}$ per $\mathrm{g}$ of soil & $2.4 \times 10^{2} \mathrm{a}$ & $2.0 \times 10^{2} \mathrm{ab}$ & $1.2 \times 10^{2} \mathrm{ab}$ & $1.1 \times 10^{2} \mathrm{~b}$ \\
\hline $\mathrm{J}_{2}+$ eggs per $\mathrm{g}$ of roots & $9.5 \times 10^{3} \mathrm{a}$ & $4.8 \times 10^{3} \mathrm{~b}$ & $4.1 \times 10^{3} \mathrm{~b}$ & $3.1 \times 10^{3} \mathrm{c}$ \\
\hline Females per $\mathrm{g}$ of roots & $9.0 \times 10 \mathrm{a}$ & $6.3 \times 10 \mathrm{~b}$ & $9.8 \times 10$ a & $6.9 \times 10 \mathrm{~b}$ \\
\hline Eggs per female & $1.1 \times 10^{2} \mathrm{a}$ & $7.7 \times 10$ a & $4.2 \times 10 \mathrm{~b}$ & $4.6 \times 10 \mathrm{~b}$ \\
\hline \multicolumn{5}{|c|}{ cv. Kyoryoku-beiju in microplots } \\
\hline $\mathrm{J}_{2}$ per $\mathrm{g}$ of soil & $4.0 \times 10 \mathrm{a}$ & $5.0 \times 10 \mathrm{a}$ & $4.9 \times 10$ a & $4.0 \times 10 \mathrm{a}$ \\
\hline $\mathrm{J}_{2}+$ eggs per $\mathrm{g}$ of roots & $2.7 \times 10^{4} \mathrm{a}$ & $2.0 \times 10 \mathrm{a}$ & $2.7 \times 10^{4} \mathrm{a}$ & $2.1 \times 10^{4} \mathrm{a}$ \\
\hline Females per $\mathrm{g}$ of roots & $2.0 \times 10^{2} \mathrm{a}$ & $1.6 \times 10^{2} \mathrm{a}$ & $1.9 \times 10^{2} \mathrm{a}$ & $1.9 \times 10^{2} \mathrm{a}$ \\
\hline Eggs per female & $1.3 \times 10^{2} \mathrm{a}$ & $1.4 \times 10^{2} \mathrm{a}$ & $1.5 \times 10^{2} \mathrm{a}$ & $1.3 \times 10^{2} \mathrm{a}$ \\
\hline
\end{tabular}

${ }^{a} \mathrm{Gm}$, inoculated with Glomus sp.; Mi, inoculated with M. incognita; Pp, inoculated with P. penetrans. Data are the means of eight replicates in the pot experiments and three replicates in the microplot experiment. Data in the same row followed by the same letter do not differ at the level of $p \leq 0.05$.

plication and by $57 \%$ when both treatments were applied together compared to soils with $M$. incognita alone. Nematode densities were lower by $34 \%$, $55 \%$ and $62 \%$, respectively, for cv. Pritz.

Number of females per $g$ of roots was reduced in mycorrhizal treatments and the number of eggs per female was reduced $(p \leq 0.05)$ in Pasteuria treat- ments (Table 2).

No significant differences were observed in mycorrhizal intensity $(\mathrm{M} \%)$ within root tissues of any of the mycorrhizal treatments $(\mathrm{Gm}$; Mi-Gm; MiGm-Pp) (Table 3).

There were no significant differences between mycorrhizal and non-mycorrhizal plants in P. pene- 
trans percentage of attachment, number of spores per $\mathrm{J}_{2}$ or percentage of infected females (Table 4).

\section{DISCUSSION}

The application of both Glomus sp. and P. penetrans partially compensated for the reduction in plant growth caused by $M$. incognita. The carriers of the inocula, without Glomus sp. or P. penetrans spores, were applied to seedlings and nematode infested soil without any apparent effect. We therefore confirmed that the beneficial effects are directly linked to the biological agents and not to chemical compounds associated with the carriers.

Table 3. Effects of M. incognita and P. penetrans on Glomus sp. colonization of tomato roots $(\mathrm{M} \%)$

\begin{tabular}{lccc}
\hline & \multicolumn{3}{c}{ Treatments $^{\mathrm{a}}$} \\
\cline { 2 - 4 } & Gm & Mi-Gm & Mi-Gm-Pp \\
\hline cv. Kyoryoku-beiju in pots & 44.2 a & $36.4 \mathrm{a}$ & $35.1 \mathrm{a}$ \\
cv. Pritz in pots & 43.0 a & $39.8 \mathrm{a}$ & $42.1 \mathrm{a}$ \\
cv. Kyoryoku-beiju in microplots & - & $24.7 \mathrm{a}$ & $26.6 \mathrm{a}$ \\
\hline
\end{tabular}

${ }^{\mathrm{a}} \mathrm{Gm}$, inoculated with Glomus sp.; Mi, inoculated with $M$. incognita; $\mathrm{Pp}$, inoculated with $P$. penetrans. Data are the means of eight replicates in the pot experiments and three plants and three replicates in the plot experiment. Data in the same row followed by the same letter do not differ at the level of $p \leq 0.05$.
The effects of Glomus or Pasteuria alone were not sufficient to overcome reductions in plant growth caused by $M$. incognita on the cultivar Kyoryoku-beiju, but when both treatments were combined, shoot weight and fruit yield were increased in comparison to nematode infested plants and nematode final densities were lower than when Glomus sp. or Pasteuria were used alone. We did not observe any significant interaction between Glomus and Pasteuria treatments. Therefore, the effects on plant growth of the combined treatment appear to be the sum of the single effects more than a synergistic interaction.

The reduction in $M$. incognita infection and reproduction by $P$. penetrans is mainly due to reduced mobility and death of spore-encumbered juveniles and reduced egg-production by females (Sano and Gaspard, 1995; Chen et al., 1996; Adiko and Gowen, 1999). From our results, there was little evidence that $P$. penetrans reduced $\mathrm{J}_{2}$ root penetration because numbers of females per $g$ of root were similar in all plants infected with $M$. incognita. However, the lower number of eggs per female in $P$. penetrans treatments suggests that the primary effect was in reducing egg laying.

Plant growth enhancement conferred by mycorrhiza has been reported for many plant species. Knowledge of mycorrhizal mechanisms that could explain this phenomenon is still scarce, but proposed hypotheses (Azcón-Aguilar and Barea,

Table 4. Effects of Glomus sp. on P. penetrans spore attachment and infection on M. incognita

\begin{tabular}{|c|c|c|}
\hline & \multicolumn{2}{|c|}{ Treatments $^{\mathrm{a}}$} \\
\hline & Mi-Pp & Mi-Gm-Pp \\
\hline \multicolumn{3}{|l|}{ cv. Kyoryoku-beiju in pots } \\
\hline Percentage of $\mathrm{J}_{2}$ with attached spores (\%) & $76.9 \mathrm{a}$ & $81.9 \mathrm{a}$ \\
\hline Spores per $\mathrm{J}_{2}$ & $5.1 \mathrm{a}$ & $6.1 \mathrm{a}$ \\
\hline Percentage of Pp infected females (\%) & $43.9 \mathrm{a}$ & $51.7 \mathrm{a}$ \\
\hline \multicolumn{3}{|l|}{ cv. Pritz in pots } \\
\hline Percentage of $\mathrm{J}_{2}$ with attached spores (\%) & $70.4 \mathrm{a}$ & $58.8 \mathrm{a}$ \\
\hline Spores per $\mathrm{J}_{2}$ & $6.8 \mathrm{a}$ & $6.2 \mathrm{a}$ \\
\hline Percentage of Pp infected females (\%) & $35.8 \mathrm{a}$ & $28.0 \mathrm{a}$ \\
\hline \multicolumn{3}{|l|}{ cv. Kyoryoku-beiju in microplots } \\
\hline Percentage of $\mathrm{J}_{2}$ with attached spores (\%) & $33.3 \mathrm{a}$ & $23.3 \mathrm{a}$ \\
\hline Spores per $\mathrm{J}_{2}$ & $1.0 \mathrm{a}$ & $1.3 \mathrm{a}$ \\
\hline Percentage of $\mathrm{Pp}$ infected females (\%) & $7.8 \mathrm{a}$ & $10.0 \mathrm{a}$ \\
\hline
\end{tabular}

\footnotetext{
${ }^{a} \mathrm{Gm}$, inoculated with Glomus sp.; Mi, inoculated with M. incognita; Pp, inoculated with P. penetrans. Data are the means of eight replicates in the pot experiments and three replicates in the microplot experiment. Data in the same row followed by the same letter do not differ at the level of $p \leq 0.05$.
} 
1996) are: (i) modification of root exudates and development of new antagonistic micro-organisms in the mycorrhizosphere that affect nematode penetration; (ii) production and accumulation of compounds such as phenols, phytoalexins and hormones within mycorrhizal root systems that affect nematode feeding; (iii) spatial competition within root tissues; and (iv) improvement in nutrient uptake by the host plant. In our experiments, mycorrhizal treatments showed lower numbers of females per $g$ of root and lower final nematode densities in soil and roots than non-mycorrhizal treatments, but no effects on the number of eggs per female were observed, suggesting that mycorrhization affected nematode penetration or nematode development.

Glomus sp. establishment, estimated in terms of intensity (M\%), was not influenced by $M$. incognita infection. Although a reduced colonization percentage and number of vesicles has been reported for most mycorrhiza-nematode interactions (Smith and Kaplan, 1988; Campubrí et al., 1993), no direct negative effect of nematodes on mycorrhizal colonization was reported in M. incognita-infected banana (Jaizme-Vega et al., 1997). It appears that there is no single response of mycorrhizal development in cortical tissues to nematode invasion and that this response may depend on various factors, such as nematode, mycorrhiza and plant species, environmental factors and period of exposure to the nematode. In most cases, mycorrhizal establishment is affected when nematodes are inoculated simultaneously to mycorrhizal fungi, but when the $\mathrm{AM}$ has colonized within the roots before nematode infection there seems to be little affect on mycorrhizal colonization. In our study, M. incognita was inoculated two or three weeks after Glomus sp., allowing the mycorrhiza to colonize a high proportion of roots before nematode infection.

No significant effects of the mycorrhizal treatment on $P$. penetrans attachment or number of $M$. incognita females infected by P. penetrans were observed. Dupponois et al. $(1997,1999)$ reported a stimulating effect of several soil bacteria on attachment of Pasteuria endospores to Meloidogyne juveniles. Rao and Gowen (1998) reported that mycorrhizal colonization of roots had an incremental effect on the number of $M$. incognita females infected by P. penetrans. We did not find any significant effect on attachment or female infection by Pasteuria. Nevertheless, the mycorrhizal species used by Rao and Gowen was G. deserticola Trappe et al., a different species from ours. We cannot discount the possibility that such effects occur under different experimental conditions.

These results show that early mycorrhizal inoculations of tomato plants together with $P$. penetrans spore application to soil are beneficial to tomato growth in soils infested with $M$. incognita. Plants grown in Glomus sp.-P. penetrans treatments showed greater plant growth either due to an increased tolerance to nematode infection or nematode suppression. There were no apparent negative interactions between application of $P$. penetrans and colonization of roots by Glomus sp. The combined treatments of both Glomus sp. and P. penetrans were superior to the application of either organism alone in $M$. incognita infested soil. Therefore, the application of these two organisms appears to be compatible and should be considered as a nematode management strategy, especially during the first years of treatment with P. penetrans.

\section{ACKNOWLEDGEMENTS}

This work was supported by a postdoctoral STA fellowship from Japan Science and Technology Agency. The authors thank Dr. Jerome Gaspard and two anonymous referees for the critical revision of this manuscript and their valuable suggestions, Dr. Motoshi Suzuki from Idemitsu Kosan Co. who kindly provided the inoculum of Glomus sp. R10 ATCC-74311 and Dr. Masanori Saito from the National Grassland Research Institute for his valuable information on obtaining the mycorrhizal inoculum.

\section{REFERENCES}

Adiko, A. and S. R. Gowen (1999) Effects of spores of Pasteuria penetrans on the motility of second-stage juveniles of Meloidogyne incognita. Rus. J. Nematol. 7: 5-6.

Azcón-Aguilar, C. and J. M. Barea (1996) Arbuscular mycorrhiza and biological control of soil borne plant pathogensan overview of the mechanisms involved. Mycorrhiza 6: $457-464$.

Bridge, J. and S. L. Page (1980) Estimation of root-knot nematode infestation levels on roots using a rating chart. Trop. Pest Manage. 26: 296-298.

Campubrí, A., J. Pinochet, C. Calvet and V. Estaún (1993) Effects of the root-lesion nematode Pratylenchus vulnus and the arbuscular mycorrhizal fungus Glomus mosseae on the growth of three plum rootstocks. Plant Soil 153: 223229.

Chen, Z. X. and D. W. Dickson (1998) Review of Pasteuria penetrans: Biology, ecology and biological control potential. J. Nematol. 30: 313-340.

Chen, Z. X., D. W. Dickson, R. McSorley, D. J. Mitchell and T. E. Hewlett (1996) Suppression of Meloidogyne arenaria 
race 1 by soil application of endospores of Pasteuria penetrans. J. Nematol. 28: 159-168.

Dupponois, R., A. M. Bâ and T. Mateille (1999) Beneficial effects of Enterobacter cloacae and Pseudomonas mendocina for biocontrol of Meloidogyne incognita with the endospore-forming bacterium Pasteuria penetrans. Nematology 1: 95-101.

Dupponois, R., C. Netscher and T. Mateille (1997) Effect of rhizosphere microflora on Pasteuria penetrans parasitizing Meloidogyne graminicola. Nematol. Medit. 25: 99109.

Giovannetti, M. and B. Mosse (1980) An evaluation of the techniques for measuring vesicular arbuscular mycorrhizal infection on roots. New Phytol. 84: 489-500.

Hooker, J. E., M. Jaizme-Vega and D. Atkinson (1994) Biocontrol of plant pathogens using arbuscular mycorrhizal fungi. In Impact of Arbuscular Mycorrhizas on Sustainable Agriculture and Natural Ecosystems (S. Gianinazzi and H. Schüepp eds.). Birkhäuser Verlag Basel, Switzerland, pp. 191-200.

Jaizme-Vega, M. C., P. Tenoury, J. Pinochet and M. Jaumot (1997) Interactions between the root-knot nematode Meloidogyne incognita and Glomus mosseae in banana. Plant Soil 196: 27-35.

Jarstfer, A. G. and D. M. Sylvia (1997) Isolation, culture and detection of arbuscular mycorrhizal fungi. In Manual of Environmental Microbiology (C. J. Hurst ed.). American Society of Microbiology, Washington, D.C., pp. 406-412.

Oostendorp, M., D. W. Dickson and D. J. Mitchell (1991) Population development of Pasteuria penetrans on Meloidogyne arenaria. J. Nematol. 23: 58-64.

Phillips, J. M. and D. S. Hayman (1970) Improved procedures for clearing roots and staining parasitic and vesicular-arbuscular mycorrhizal fungi for rapid assessment of infection. T. Brit. Mycol. Soc. 55: 158-161.

Rao, M. S. and S. R. Gowen (1998) Bio-management of Meloidogyne incognita on tomato by integrating Glomus deserticola and Pasteuria penetrans. Z. Pf-krank. Pfschuz. 105: 49-52.

Sano, Z. and J. T. Gaspard (1995) Differences in mortality and reproduction of Meloidogyne incognita infected with varied amounts of Pasteuria penetrans. Jpn. J. Nematol. 25: 129.

Smith, G. S. and D. T. Kaplan (1988) Influence of mycorrhizal fungus, phosphorus and burrowing nematode interactions on growth of rough lemon citrus seedlings. J. Nematol. 20: 539-544.

Stirling, G. R. (1984) Biological control of Meloidogyne javanica with Bacillus penetrans. Phytopathology 74: 5560.

Stirling, G. R., R. D. Sharma and J. Perry (1990) Attachment of Pasteuria penetrans spores to the root-knot nematode Meloidogyne javanica in soil and its effects on infectivity. Nematologica 26: 308-312.

Talavera, M., K. Itou and T. Mizukubo (2001) Reduction of nematode damage by root colonization with arbuscular mycorrhiza (Glomus spp.) in tomato-Meloidogyne incognita (Tylenchida: Meloidogynidae) and carrot-Pratylenchus penetrans (Tylenchida: Pratylenchidae) pathosystems. Appl. Entomol. Zool. 36: 387-392.

Verdejo-Lucas, S. (1992) Seasonal population fluctuation of Meloidogyne spp. and the Pasteuria penetrans group in kiwi orchards. Plant Disease 76: 1275-1279. 